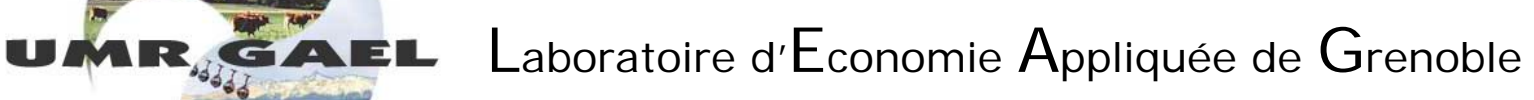

SEEMINGLY COMPETITIVE FOOD RETAIL REGULATIONS :

WHO DO THEY REALLY HELP ?

LARUE Bruno ; BONROY Olivier

July 2008

Working Paper GAEL ; 2008-04

Institut National de la Recherche Agronomique - Université Pierre Mendès France Unité Mixte de Recherche 1215

Domaine Universitaire - BP 47 - 38040 GRENOBLE Cedex 9

Tél. : 33 (0) 476825439 - Fax : 33 (0) 476825455

E-mail : vertier@grenoble.inra.fr - http://www.grenoble.inra.fr

$P$ I $E R R E$. . .

$M E N D E S$.

f R A N C E " -

Grenoble 2 Sciences Sociales 


\title{
Seemingly Competitive Food Retail Regulations: Who Do They Really Help?
}

\author{
Bruno Larue* \\ Canada Research Chair in International Agri-food Trade \\ CRÉA, Laval University \\ bruno.larue@eac.ulaval.ca \\ And \\ Olivier Bonroy \\ GAEL, INRA-Pierre Mendès France University \\ CRÉA, Laval University \\ olivier.bonroy@grenoble.inra.fr
}

July 2008

\begin{abstract}
The food distribution and retail sectors in Quebec are highly concentrated and integrated as large food distributors are also involved in food retailing. As such, they are competing with small grocery and convenience stores they sell inputs to. A review of the industry suggests that there are important economies of size in distribution, but that smaller stores offering convenience face a more inelastic demand. Concerns over the survival of smaller stores in Quebec have motivated two types of regulations. The first type aims at reducing the cost advantage of dominant retailers by restricting the number of employees that they are allowed to use during specific time periods. The second type restricts retail prices. We develop a simple model capturing the main features of the industry to ascertain the impact of these regulations on retail and wholesale prices. Our results suggest that these regulations reduce welfare and may induce both tighter margins and lower surplus for small retailers.
\end{abstract}

Keywords: Food retail regulations, food distribution, vertical integration, cost predation.

J.E.L. Classification: L22

\footnotetext{
* Larue is the corresponding author: Department of Agricultural Economics and Consumer Studies, Laval University, QC, Canada G1K 7P4.
} 


\section{Seemingly Competitive Food Retail Regulations: Who Do They Really Help?}

\section{INTRODUCTION}

Market power has been a perennial issue in agri-food markets. The existence of many Canadian institutions, like marketing boards and state-trading agencies, has been motivated to a large extent by concerns for “competitive” family farm operators and their ability to obtain "fair” prices in dealing with large input suppliers, processors and traders. A few years ago, questions were raised about the market power of processors and retailers when beef retail prices failed to follow the spectacular drop in cattle prices caused by the discovery of a "mad" cow. In this case as in many others, it was the welfare of farmers, and not so much that of consumers, that prompted calls for investigation and intervention. However, concerns about small firms and the welfare implications of deeper vertical integration are also manifest at the food retail level. In this paper, we analyze the effect of two regulations designed to help small grocery stores and convenience stores compete against large distributors forwardly integrated in the food retail business. To do so, we rely on a simple fixed-proportions model of forward vertical integration involving large food distributors selling to and competing with small independent food retailers. While our forward integration model shares many features with the classic models of Riordan (1998) and Salop and Scheffman (1987), it produces significantly different results that have interesting policy implications for the food retail business.

In the province of Quebec, a law adopted in 1992 forced large food retailers to limit to four the number of employees working after 21:00 on week days and after 17:00 on Saturdays and Sundays as well as on designated holidays. The law was slightly relaxed on December $13^{\text {th }}$ of 2006 by changing the trigger hour from 17:00 to 20:00. When the law was being drafted, it had been expected that large food retailers would reduce their business hours rather than operate 
with only four employees, the number of employees commonly used in small stores. ${ }^{1}$ Thus, the purpose of the law was to improve the ability of small grocery stores and convenience stores to compete in a market dominated by a few large-scale food retailers. It had been hoped that easing the competition over specific time periods would improve the profitability of small firms and in the end enhance overall competition. Contrary to the government's expectation, large food retailers responded to the regulation by extending their business hours, betting that long lines at the check-out would create less inconvenience for their customers than shorter business hours. The law is controversial. On the one hand, large retailers would like more flexibility and have challenged it by having more than four employees working during holidays. Metro, LoblawProvigo and IGA also distributed 300000 post-cards (with pre-paid postage and a bilingual list of arguments for more flexibility) to make it easier for their customers to complain to the elected members of Quebec's National Assembly. ${ }^{2}$ Small stores and unions called for an end to the fouremployee rule and requested that shorter business hours be imposed on large retailers. The added flexibility from the 2006 modification to the law has not settled the issue because large grocery stores openly challenge the law by having more than four employees during holidays. ${ }^{3}$ Our model shows that raising the cost of large food retailers through restrictions on the number of employees allowed to work after certain hours is bad for consumers and can actually be bad for small retailers as well, the group the law is meant to protect.

The second restriction pertains to setting minimum retail prices for certain products like milk and beer. It was hoped that the imposition of minimum retail prices on certain items would prevent large scale retailers to eject smaller stores out of the market, but we show that a minimum retail price may exacerbate the aggressive behavior of the integrated distributor toward independent retailers. 
The next section discusses vertical integration in the distribution and food retail sectors in Canada. Similarities and contrasts between Quebec and other provinces are highlighted. This sets up the stage for the description of our model in section 3. Section 4 analyzes the effects of artificially increasing the marginal retail cost of large retailers through regulations. Section 5 investigates the effect of imposing a binding minimum price in small retail outlets. Section 6 summarizes our main results and dwells on the unintended consequences of government interventions meant to protect the "small”, like the convenience stores and small independent grocery stores at the retail level, or the small family farms at the primary production level.

\section{VERTICAL INTEGRATION, FOOD DISTRIBUTION AND RETAIL}

Vertical integration has been and still is a phenomenon of empirical significance that has spurred many debates over the years. ${ }^{4}$ The food distribution and retail sectors in Canada are generally highly concentrated and integrated. Loblaws, Metro and Sobeys/IGA are the three major food retailers and distributors in Quebec. ${ }^{5}$ The retail market in Quebec differs from its counterpart in Ontario. Supermarket sales in Quebec (Ontario) in 2005 amounted to \$14.25 (21.45) billions while convenience stores/dépanneurs and specialized food stores sold for \$3.48 (2.65) billions. ${ }^{6}$ These statistics unmistakably show that supermarkets get a much larger share of every dollar spent on food in Ontario than in Quebec and the difference is going to get only larger with increases in the number of Walmart's superstores in English Canada. ${ }^{7}$ Different factors can explain the relative importance of smaller stores in Quebec. The fact that beer is still strictly sold in beer stores in Ontario is a major impediment to the growth of convenience stores. In Quebec, supermarkets and convenience stores are allowed to sell beer and a limited selection of wines, but these items represent a much larger share of total sales for convenience stores. It is also worth 
pointing out that patronizing specialized shops, like butcher shops and pastry shops, seems more common in Quebec, probably because of the French heritage in that province.

The major players’ importance and strategies vary across provinces. For example, a large national food distributor like Sobeys currently has 343 corporate stores and 43 franchised stores in Atlantic Canada as opposed to 16 (71) corporate stores and 341 (118) franchised stores in Quebec (Western Canada). There are economies of scale in food distribution and this is why there are so few firms. Even Canada's largest distributor, Loblaws, has undergone a significant "supply chain restructuring to a more efficient network of fewer, butt larger facilities (Loblaws, 2005 p.3). These economies of scale originate from various sources. First, the development of computerized inventory management systems has made it easy to handle very large volumes of perishable products. Second, fewer firms can better optimize the location and product mix of distribution centers to reduce handling and transport costs. For example, Metro has 4 warehouses for grocery products and 2 for meats. Third, there is the simple, yet very germane, issue of lumpiness in the transport of food. This is especially important for stores located in less populated areas. For such cases, it costs very little at the margin for a distributor to "completely fill the truck” and supply their corporate or franchised grocery store as well as competing stores at the same time. As a result, large food distributors have agreements amongst themselves to exploit logistic efficiency.

Large food distributors supply many different types of stores and the relationships between the stores and the distributors vary. For example, Metro supplies 576 supermarkets in Quebec and Ontario (under the Metro, SuperC, Loeb, Food Basics and A\&P banners), 225 smaller grocery stores (119 Marché Richelieu, 97 Marché Ami, 9 The Barn) and 289 convenience stores Gem. In all, it supplies 2000 small-surface stores of which 800 are under one of its banners (eg., SOS Dépanneur, Marché Extra, Servi Express). It also supplies several drugstores 
(e.g., Brunet and CliniPlus). ${ }^{8}$ Loblaws is similarly involved, having various kinds of agreements with stores it supplies. It is stated in its 2005 annual report that it supplies 670 corporate stores, 402 franchised stores, 472 associated stores in addition to having 7858 independent accounts!

The convenience store business has changed tremendously over the years in Quebec and in the rest of Canada. The most important change has been the emergence of Couche-Tard as the largest Canadian convenience retailer and the third largest in North America. ${ }^{9}$ Couche-Tard is now big enough to manage its own distribution network, but it is a recent phenomenon, as it is only in 2002 that its new distribution center located in Montreal became operational. Still, the dominance of the top 3 distributors over distribution and retail remains unquestioned because of their size.

At the retail level, the major players across Canada are increasingly relying on very large stores to offer more products and services, perhaps in response to Walmart's superstores and to Costco stores. Loblaws has made major investments in its Ontario superstores ${ }^{10}$ and Metro significantly invested in its largest outlets, like Super C (48 in 2002 against 56 in 2005) and Metro Plus stores. Sobeys did the same in Quebec with its IGA Extra stores. In fact, the ratio of investment in buildings by food stores as opposed to general merchandise stores was higher in Canada than in the United States in 2005. ${ }^{11}$ Bigger retail stores appeals to busy consumers who can buy a wide range of products under one roof. Corner stores cater to consumers who “don't want to drive on the other side of town" to get a few staples. As such, both types of stores offer convenience in their own way. Because consumers differ in terms of their location relative to the closest corner store and supermarket and in terms of their appreciation for selection and the opportunity cost of their time, it is safe to assume that corner stores and supermarkets face different yet related demand functions. 


\section{PARTIAL FORWARD VERTICAL INTEGRATION AND THE INCREASING DOMINANCE OF LARGE RETAILERS}

Large food distributors are forwardly integrated in the retail business, but their integration is partial as they compete with smaller retailers they sell inputs to. The literature on vertical integration has distinguished two sets of cases, depending on whether the input requirement per unit of output is fixed or variable with the level of output. In the case of food distribution and retail, the fixed-proportion assumption is most appropriate because more often than not retailers have only to unpack the goods delivered by the distributor. The fixed-proportion assumption remains valid even when some packaging must be done by retailers. Most textbooks, as early as Needham (1969) and as recently as Church and Ware (2000), discuss a fixed-proportion case in which downstream production is accomplished with a widely available constant (average) cost technology and upstream production is controlled by a monopolist. The appeal of this case is that it demonstrates that forward vertical integration can be pointless; the non-integrated monopolist

being equally able to exploit the downstream demand as it would under an integration scenario. ${ }^{12}$ If the upstream monopolist was able to secure a better constant cost technology for downstream production, it would fully integrate by displacing or purchasing all of the competitive firms. Given this “razor's edge” effect, which is observed in other models as well, one must appeal to regulations to rationalize the existence of a partial integration outcome ${ }^{13}$ or give up on the constant unit cost assumption as Bonroy and Larue (2007). Partial integration and the small number of distributors characterize the distribution/retail industry in Quebec. In order to shed some light of recent issues, we develop a model with $n$ forwardly integrated food distributors, each selling a quantity $q_{i}$ at the retail level and supplying a quantity $x_{i}$ to small price-taking retailers with whom they have exclusive contracts. 
A few large food distributors share the upstream market (distribution) and are involved in the downstream market (retail) as well. As such, each distributor is the sole input supplier for its own fringe of small retailers with which it competes at the retail level. For simplicity, a competitive fringe of small retailers selling a quantity $x_{i}$, face an inverse demand curve $R=a-b \sum_{j=1}^{n} x_{j}-\gamma \sum_{j=1}^{n} q_{j}$, where $R$ is the retail price for goods sold by small retailers or corner stores, $q_{j}$ is the volume sold by supermarket $j$ and $\gamma$ is a parameter capturing the extent of product differentiation between corner stores and supermarkets. All small retailers are assumed to sell a homogenous bundle and the same goes for supermarkets whose inverse demand is given by: $P=A-B \sum_{j=1}^{n} q_{j}-\gamma \sum_{j=1}^{n} x_{j}$. Products sold in large and small stores are substitutes (complements) if $\gamma>(<) 0$ (Vives, 1999 p.145). These linear inverse demand functions are derived from the following utility function: $U=A Q+a X-0.5\left(B Q^{2}+b X^{2}\right)-\gamma Q X+Z$, where aggregate consumption in large supermarkets is $Q \equiv \sum_{j=1}^{n} q_{j}$, aggregate consumption in smaller retail outlets is $X \equiv \sum_{j=1}^{n} x_{j}$ and $\mathrm{Z}$ is an aggregator for all other goods and services. Our quasi-linear function allows us to restrict our analysis to a partial equilibrium framework and to appeal to standard surplus measures to make inferences about welfare changes. ${ }^{14}$ By definition, consumer surplus is given by: $C S \equiv U-P Q-R X-Z=\frac{1}{2} B Q^{2}+\frac{1}{2} b X^{2}+\gamma Q X$ and it is increasing in both $Q$ and $X$. The above set of inverse demand functions give rise to kinked demand functions. For example, the demand facing large retailers can be written as: $Q(P, R)=\operatorname{Max}\left\{0, \operatorname{Min}\left(\alpha-\eta P+\kappa R, \frac{A-P}{B}\right)\right\}, \quad$ where $\quad \alpha \equiv \frac{A b-a \gamma}{b B-\gamma^{2}}, \eta \equiv \frac{b}{b B-\gamma^{2}}, \kappa \equiv \frac{\gamma}{b B-\gamma^{2}}$ 
because there is a critical price $P$ below which only large retailers remain. However, we will assume throughout that there are strictly positive demands for both types of stores.

Each firm involved in retailing activities relies on a fixed-proportion technology. The goods purchased by retailers from the distributor are referred to as inputs and one unit of input is required to produce one unit of output. The cost functions for large and small scale retailing are respectively $C^{L}\left(q_{i}\right)=c q_{i}+\frac{d}{2} q_{i}^{2}$ and $C^{s}\left(x_{i}\right)=\frac{\delta}{2} x_{i}^{2}$, where $c \geq 0, d \stackrel{\geq}{<} 0$ and $\delta>0$. As such the marginal cost of larger retailers can be upward sloping, constant or downward sloping while that of small competitive retailers is strictly increasing. When $c=0, d=\delta$, large and small retailers share the same technology characterized by decreasing returns. Cost advantages could be given to large retailers, as in Riordan (1998) or Bonroy and Larue (2007) who showed that partial forward integration by a upstream monopolist is consistent with moderate cost advantages and cost disadvantages in downstream/retailing activities. We assume that the cost of distributing services can be proxied by $C^{D}\left(q_{i}+x_{i}\right)=e\left(q_{i}+x_{i}\right)+\frac{f}{2}\left(q_{i}+x_{i}\right)^{2}$, where $e>0, f \underset{<}{<} 0$ so as to accommodate decreasing, constant and increasing returns in distribution services.

Each individual retailer is too small to have market power and it is assumed that these small retailers are not capable of exercising jointly any market power. The supply curve of small retailers supplied by distributor $i$ is denoted by $S_{i}(R, r)$ and it is defined by: $:^{15}$

$$
x_{i}(R, r) \equiv \underset{x_{i}}{\operatorname{Arg} \max } \pi_{i}^{s}=\operatorname{Max}(0,(R-r) / \delta)
$$

where $\pi_{i}^{s} \equiv\left[(R-r) x_{i}-\frac{\delta}{2} x_{i}^{2}\right]-K_{i}$, where $K_{i}$ is a fee levied by the distributor $i$ to get part or all of the profit made by the small retailers it contracts with. ${ }^{16}$ This fee is usually paid upfront and can be seen as a sunk cost. Because it impacts only on the distribution of rents between small retailers 
and distributors and not on the aggregate level of rents, it does not impact on our subsequent results. Because of the fixed-proportion assumption, the supply of the small retailers is conditioned by the price differential $R-r$. As such it is increasing in the retail price, $x_{i R} \equiv \partial x_{i}(.) / \partial R=1 / \delta$, declining in the input price, $x_{i r} \equiv \partial x_{i}(.) / \partial r=-1 / \delta$ and $x_{i R}=-x_{i r}$, $X_{i R R}=X_{i r r}=X_{i R r}=0$. The second order condition simply requires that $\delta>0$.

Distributor $i$ entertains Cournot conjectures about rival distributors and knows the technology used by small retailers as well as the demand function for their product. It can invert the supply relation in (1) and use the market demand facing small retailers to obtain a price schedule: $r_{i}=R-\delta x_{i}=a-b \sum_{j=1}^{n} x_{j}-\gamma \sum_{j=1}^{n} q_{j}-\delta x_{i}$. Distributor $i$ maximizes its profit $\pi_{i}^{D}$ which is the sum of his revenues as a large retailer $\left(P q_{i}\right)$ and his revenues as a supplier to small retailers $\left(r_{i} X_{i}\right)$ minus the sum of retailing cost $C^{L}\left(q_{i}\right)$ and distributing costs $C^{D}\left(q_{i}+x_{i}\right)$ :

$$
\begin{aligned}
\max _{q_{i}, x_{i}} \pi^{D}= & {\left[\left(A-B \sum_{j=1}^{n} q_{j}-\gamma \sum_{j=1}^{n} x_{j}\right) q_{i}+\left(a-b \sum_{j=1}^{n} x_{j}-\gamma \sum_{j=1}^{n} q_{j}-\delta x_{i}\right) x_{i}+K_{i}\right.} \\
& \left.-c q_{i}-\frac{d}{2} q_{i}^{2}-e\left(q_{i}+x_{i}\right)-\frac{f}{2}\left(q_{i}+x_{i}\right)^{2}\right]
\end{aligned}
$$

The first order conditions describing the choices about quantities to be sold in large and small retail outlets by distributor i are:

$$
\begin{gathered}
\left(A-B \sum_{j=1}^{n} q_{j}-\gamma \sum_{j=1}^{n} x_{j}\right)-(B+d+f) q_{i}-(\gamma+f) x_{i}-(c+e) \leq 0 \\
\left(a-b \sum_{j=1}^{n} x_{j}-\gamma \sum_{j=1}^{n} q_{j}-\delta x_{i}\right)-(b+f+\delta) x_{i}-(\gamma+f) q_{i}-e \leq 0
\end{gathered}
$$

The second order condition requires that $H \equiv-(f+2 \gamma)^{2}+(2 B+f+d)(2 b+f+2 \delta)>0$. We will assume throughout that the expressions $(2 B+f+d)$ and $(2 b+f+2 \delta)$ are strictly positive. 
Thus, the second order condition constrains the substitution parameter $\gamma$ in the demand functions not to be too large in absolute value relative to the own-price parameters $B$ and $b$. Because we posit that large retailers face a more elastic demand than small ones, we assume that: $b>B>\gamma>0$ and $a>A$. The second order condition allows for decreasing and moderately increasing returns in distribution as $f$ can be positive or negative. Assuming that an interior solution exists to make the above inequalities hold with equality and that firms are symmetric such that $q_{i}=q_{j}=q, x_{i}=x_{j}=x \forall i \neq j$, and $\sum_{j=1}^{n} q_{j}=n q, \sum_{j=1}^{n} x_{j}=n x$, we can rewrite the first order conditions as follows:

$$
\begin{gathered}
(A-c-e)-(B(n+1)+d+f) q-(\gamma(n+1)+f) x=0 \\
(a-e)-(\gamma(n+1)+f) q-(b(n+1)+2 \delta+f) x=0
\end{gathered}
$$

These two equations can be solved to find the equilibrium solutions for $q$ and $x$ :

$$
\begin{aligned}
& q=-\frac{(a+c) f+b(c+e)(n+1)+(a-e) \gamma(n+1)+2 \delta(c+e)-A(b(n+1)+f+2 \delta)}{d f+b(n+1)(B(n+1)+d+f)-\gamma(n+1)(2 f+\gamma(n+1))+2 \delta(d+f)+B(n+1)(f+2 \delta)} \\
& x=\frac{a(B(n+1)+d+f)-B e(n+1)-(A-c+e)(n+1) \gamma-d e-(A-c) f}{d f+b(n+1)(B(n+1)+d+f)-\gamma(n+1)(2 f+\gamma(n+1))+2 \delta(d+f)+B(n+1)(f+2 \delta)}
\end{aligned}
$$

Partial integration is a "natural" outcome in this model and competition regulations do not need to be invoked, as in Quirmbach (1992), to justify the presence of small independent retail stores in the market. ${ }^{17}$ To see this, consider an example in which the distributor has the same retail technology as the small retailers. More specifically, let $c=0, d=\delta=0.2$, and in line with our assumption that large retailers face a more elastic demand than the small retailers, we set $A=10, a=14, B=0.35, b=1, \gamma=0.2$ and have decreasing returns in distribution, $e=0, f=0.1$. Figure 1 shows how retail quantities $q$ and $x$ change as the number of distributors increases. 
Naturally, more distributors mean that each distributor sells smaller quantities through its retail outlets and through smaller retailers. The interesting aspect of this example is that it does not appeal to cost advantages or economies of size in retail to rationalize the larger market share of integrated retailers. The point is not contest the "real-life" existence of a cost advantage for large retailers, but to neutralize its effect on sales to gain some intuition. Thus, by construction small and large retailers have the same technology and the predominance of integrated retailers is demand-driven to reflect that "low prices" bring consumers in large grocery stores while the need for "convenience" insures that small retailers have customers. It is worth noting that the relative importance of small retailers decreases with the number of distributors. Put differently, large integrated grocery stores capture a larger share of the retail market as competition intensifies between distributors. The demand faced by large integrated retailers being more elastic than that of small retailers implies that $n^{*} q$ grows faster than $n^{*} x$ as the number of distributors increases. Even though we do not have a location model, a parallel can easily be made in the sense that increases in the number of supermarkets decreases the demand for "convenience". This helps explains the increasingly dominant position of large integrated retailers, which could be further enhanced by technological changes favoring larger outlets. Naturally, prices in large and small retail outlets decrease with the number of distributors in our example. We can infer that the presence of new players like Wal-Mart in the Canadian food retail business contributes to keep food prices low by competing with existing large and small retailers for customers. In this light, Loblaw's massive investments to improve efficiency in distribution and the lobbying efforts made by small retailers to obtain accommodating regulations are not surprising.

Even though the quantities sold be large and small retailers, the $q$ and $x$ expressions, are rather messy, we can exploit the simplicity of our model through standard comparative statics that will help us derive results about changes in equilibrium quantities and prices. 
LEMMA 1: i) changes in sales in response to changes in demand parameters: $\partial q / \partial A=(2 b+2 \delta+f) / H>0, \partial x / \partial A=-(2 \gamma+f) / H \underset{>}{\leq} 0, \partial q / \partial a=-(2 \gamma+f) / H \stackrel{\leq}{>} 0$ $\partial x / \partial a=(2 B+d+f) / H>0, \partial q / \partial \gamma=[((2 \gamma+f) q-(2 b+2 \delta+f) x)(n+1)] / H \underset{<}{\stackrel{>}{<}} 0$, $\partial x / \partial \gamma=[((2 \gamma+f) x-(2 B+d+f) q)(n+1)] / H<0, \partial q / \partial B=-[(n+1) q](\partial q / \partial A)<0$, $\partial x / \partial B=-[(n+1) q](\partial x / \partial A) \leq 0, \partial q / \partial b=-[(n+1) x](\partial q / \partial a) \underset{<}{<} 0$, $\partial x / \partial b=-[(n+1) x](\partial x / \partial a)<0$, where $H \equiv-(f+2 \gamma)^{2}+(2 B+f+d)(2 b+f+2 \delta)>0 ;$

ii) changes in sales in response to changes in large retailers' cost: $\partial q / \partial c=-\partial q / \partial A<0, \partial x / \partial c=-\partial x / \partial A \underset{<}{\geq} 0, \partial q / \partial d=-q(\partial q / \partial A)<0, \quad \partial x / \partial d=-q(\partial x / \partial A) \frac{<}{>} 0$ iii) changes in sales in response to changes in the small retailers' cost: $\partial q / \partial \delta=-2 x(\partial q / \partial a) \underset{<}{\geq} 0, \partial x / \partial \delta=-2 x(\partial x / \partial a)<0 ; i v)$ changes in sales in response to changes in distributing cost: $\partial q / \partial e=-(\partial q / \partial A)-(\partial x / \partial A)<0, \partial x / \partial e=-(\partial x / \partial a)-(\partial q / \partial a)<0$, $\partial q / \partial f=(q+x)(\partial q / \partial e)<0, \partial x / \partial f=(q+x)(\partial x / \partial e)<0$

PROOF: See the appendix.

Upward shifts in the intercept of the demand faced by large (small) retailers increase the sales of large (small) retailers and have ambiguous effects on the sales of small (large) retailers. An increase in the substitution parameter $\gamma$ has an ambiguous effect on sales by large retailers, but a negative effect on sales by small retailers. Making the slope of the demand faced by large (small) retailers more inelastic, or increasing $B(b)$, tends to reduce the sales of large (small) retailers, but it has an ambiguous effect on the sales of small (large) retailers. The results with respect to "c" are about shifts in the marginal retailing cost for large integrated stores. An increase in "c" decreases the volume sold by larger retailers and it may increase or decrease the volume sold by 
small retailers. Riordan (1998) and Bonroy and Larue (2007) used this parameter to define a “cost advantage/disadvantage” for a large retailer and to define bounds separating corner solutions from equilibria involving forward partial integration or the coexistence of a large integrated firm and a fringe of small ones. As in these papers, it can be shown that large retailers with a cost advantage over small retailers need not eject small retailers and similarly large distributors need not exit the retail business even when they have a cost disadvantage. An increase in " $d$ " makes large retailers' marginal cost steeper and this too tends to decrease the volume sold by large retailers and the effect of small retailers is ambiguous. An increase in $\delta$ makes the marginal cost of small retailers steeper and this in turn depresses the sales of small retailers while having an ambiguous effect on the sales of large retailers. Finally, increases in the intercept and in the slope of the marginal distributing cost reduce both $q$ and $x$.

The large number of ambiguities in lemma 1 highlights the importance of vertical linkages between distribution and retail activities. Even though large and small retailers compete for consumers, their cost and hence behavior is very much affected by the characteristics of the technology used in distribution. Lemma 2 below shows how retail prices and the price paid by small retailers change as the levels of sales by large and small retailers change.

LEMMA 2: Given symmetric firms: i) If $d q>(<) 0, d x>(<) 0$ then $d P<(>) 0, d R<(>) 0$ and $d(P-R) \underset{<}{\geq} 0$ as $d q \frac{\leq}{>}\left(\frac{\geq}{<}\right) \frac{-(\gamma-b)}{(B-\gamma)} d x$; ii) If $d q>0, d x<0$ then $d P \stackrel{\geq}{<} 0$ as $d q \frac{<-\gamma}{>} d x, d R \underset{<}{<} 0$ as $d q \frac{<-b}{\gamma} d x$ and $d(P-R)<0$; iii) If $d q<0, d x>0$ then $d P \underset{<}{\geq} 0$ as $-d q \underset{<}{<} \frac{>}{B} d x, \quad d R \underset{<}{\geq}$ as $-d q \leq \frac{b}{\gamma} d x$ and $d(P-R)>0 ; d r=d R-\delta d x-x d \delta$.iv) Changes in welfare are given by: $d W=(B q+\gamma x) d Q+(b x+\delta x+\gamma q) d X$, where $Q \equiv n q$ and $X \equiv n x$. 
PROOF: Parts i)-iii) follow from the assumption of symmetric firms which allow us to express prices in large and small retail outlets as : $P=A-B n q-\gamma n x$ and $R=a-b n x-\gamma n q$. The results are obtained by differentiating these equations with respect to $q$ and $x$. Part iv) rests on the definition of welfare, which is simply the sum of consumer surplus, $C S=\frac{1}{2} B Q^{2}+\frac{1}{2} b X^{2}+\gamma Q X$, and the aggregate profit/surplus of the integrated distributors/large retailers and small retailers: $n\left(\pi^{d}+\pi^{s}\right)=(A-c-e) Q-\left(B+\frac{d+f}{2 n}\right) Q^{2}-\left(2 \gamma+\frac{f}{n}\right) X Q+(a-e) X-\left(b+\frac{\delta+f}{2 n}\right) X^{2} . \quad$ Hence $W=(A-c-e) Q-\frac{1}{2}\left(B+\frac{d+f}{n}\right) Q^{2}+(a-e) X-\frac{1}{2}\left(b+\frac{\delta+f}{n}\right) X^{2}-\left(\gamma+\frac{f}{n}\right) Q X \quad$ and $d W=\left[(A-c-e)-\left(B+\frac{d+f}{n}\right) Q-\left(\gamma+\frac{f}{n}\right) X\right] d Q+\left[(a-e)-\left(b+\frac{\delta+f}{n}\right) X-\left(\gamma+\frac{f}{n}\right) Q\right] d X$

From (5) and (6), we find that $(a-c-e)=\left(B+\frac{(B+d+f)}{n}\right) Q+\left(\gamma+\frac{(\gamma+f)}{n}\right) X$ and $(a-e)=\left(\gamma+\frac{(\gamma+f)}{n}\right) Q+\left(b+\frac{(b+2 \delta+f)}{n}\right) X . \quad$ Inserting these expressions in the welfare change expression, we get: $d W=(B q+\gamma x) d Q+(b x+\delta x+\gamma q) d X$. QED

Obviously, welfare increases (decreases) when both $Q$ and $X$ increase (decrease). If $d Q>0>d X$ or if $d X>0>d Q$, welfare increases if: $d q>\frac{-(b x+\delta x+\gamma q)}{(B q+\gamma x)} d x$.

\section{REGULATING THE NUMBER OF EMPLOYEES OF LARGE RETAILERS}

As argued in the introduction, the purpose of the Quebec law limiting the number of employees allowed to work after 20:00 on weekends and after 21:00 on week days in large grocery stores is to make small food retailers and convenience stores more competitive. It was hoped that large 
food retailers would close early and let smaller stores benefit from captive consumers. This would have in turn allowed small retailers to better withstand the competitive pressures from large distributors/retailers. Regulations, like taxes, can be used to create asymmetries between firms that may be welfare-enhancing (e.g., Salant and Shaffer, 1999; Larue and Gervais, 2002). A restriction on the use of an input is tantamount to forcing a more expensive set of inputs to produce the same quantity of output. Accordingly, its effect differs from that of a tax. This is illustrated in Figure 2 which for simplicity is based on a two-input Cobb-Douglas technology. We assume that the inputs are labour (x-axis) and an aggregate input (y-axis). Three isoquants are drawn for levels of output $q=3,4,5$. Given a factor price ratio, the unrestricted expansion path is a straight line emanating from the origin. It is defined by the points of tangency between the isoquants and the isocost lines. Our labour/number of employee restriction implies that additional increases in output can only be achieved by increasing the level of the aggregate input once the maximum number of employees allowed has been reached. This rationalizes the kink and the vertical segment of the restricted expansion path. In our example, the labour restriction starts binding at output level $q=3$. Beyond this level of output, increases in output are more costly under the regulation. This can be readily seen by comparing the (long-dashed) isocost line that is just tangent to the isoquant for $q=4$ to the (small-dashed) isocost line above it that cuts the isoquant and the restricted expansion path. These isocost lines are associated with costs of 9.27 and 9.65, for a ratio of 1.04 . Therefore, the restriction "shifts" the marginal cost curve. Comparing the isocost lines to produce $q=5$, we get 11.88 and 13.39 for the unrestricted and restricted cases for a ratio of 1.13 . Clearly, as the output to be produced increases, the marginal rate of substitution increases and the restriction becomes increasingly costly. As a result, the slope of the marginal cost curve increases. In our model, these effects boil down to increases in parameters " $c$ " and " $d$ " that pertain to the intercept and slope of the marginal cost of large 
retailers. From lemma 1, the effects of "d" on $q$ and $x$ are proportional to the effect of "c". Therefore, we can concentrate our attention on the effects of "c" to understand the effects of the regulation. From lemma 1, we know that: $\quad-\frac{\partial q}{\partial c}=\frac{2 b+2 \delta+f}{H}>\frac{\partial x}{\partial c}=\frac{2 \gamma+f}{H}>0$ since $\{b, B\}>\gamma$, and it follows that:

$$
\frac{d P}{d c}=-B n \frac{\partial q}{\partial c}-\gamma n \frac{\partial x}{\partial c}>0
$$

The price in large retail stores necessarily increases, which is what one would expect from firms with market power facing higher costs. The effect on prices paid by consumers in small retail stores is given by:

$$
\frac{d R}{d c}=-\gamma n \frac{\partial q}{\partial c}-b n \frac{\partial x}{\partial c}=\frac{-2 b f n+2 \gamma \delta n+\gamma f n}{H} \geq 0
$$

The above expression is positive if there are economies of size (i.e., $f<0$ ) because $b>\gamma$, but it can be negative when there are diseconomies of size and the degree of substitution between products sold in large and small retail outlets (i.e., $\gamma$ is small relative to $b$ ). The notorious cost predation effect of Salop and Scheffman (1983, 1987) predicts that a partially-vertically integrated dominant firm may find it profitable to increase the cost of fringe firms. In our case, the input price of small retailers can increase or fall in response to an improvement in the cost advantage of large retailers depending on the distribution (upstream) technology.

$$
\frac{d r}{d c}=-\frac{2 b f n}{H} \underset{<}{<} 0 \text { as } f \frac{<}{>} 0
$$

PROPOSITION 1: Consumer surplus and welfare fall in response following a regulationinduced upward shift in the marginal cost of large retailers. 
PROOF: From Lemma $1,-\frac{\partial Q}{\partial c}=n\left(\frac{2 b+2 \delta+f}{H}\right)>\frac{\partial X}{\partial c}=n\left(\frac{2 \gamma+f}{H}\right)$ and totally differentiating consumer surplus, $d C S=B Q d Q+b X d X+\gamma(X d Q+Q d X)=d Q(B Q+\gamma X)+d X(b X+\gamma Q)$. Let us assume that $f>0, A \approx a, B \approx b, c=0, d \approx \delta$ and hence that $Q \approx X$. In this instance, consumer surplus strictly decreases given that $-\frac{\partial Q}{\partial c}>\frac{\partial X}{\partial c}>0$. Naturally, if we assume that large retailers have a dominant position, $Q \gg X$, then consumer surplus will fall even more in response to an increase in " $c$ ". An increase in " $c$ " lowers the profit of the integrated firms and given that consumer surplus falls, welfare must decrease. To see this, we can apply lemma 2 to show that welfare falls provided $-\frac{\partial q}{\partial c}>\frac{(b x+\delta x+\gamma q)}{(B q+\gamma x)} \frac{\partial x}{\partial c}$. This inequality is clearly satisfied when $\partial x / \partial c<0$ or when $x$ is small relative to $q$ (e.g, consider $x \rightarrow 0$ ) which is consistent with the stylized facts of food retail in Canada. However, let us assume again that $A \approx a \quad b \approx B$, $c=0, d=\delta$ and $q \approx x$, then the welfare condition becomes $-\frac{\partial q / \partial c}{\partial x / \partial c}=\frac{2 b+2 \delta+f}{2 \gamma+f}>\frac{b+\delta+\gamma}{b+\gamma}$ which clearly holds when $f$ is small . For example, if $f=0$, the inequality boils down to $B(b+\delta)>\gamma^{2}$ which holds given $\{b, B\}>\gamma$ and $\delta>0$. Because the ratio $\frac{2 b+2 \delta+f}{2 \gamma+f}$ is decreasing in $f$, it follows that the condition will be respected when $f<0$. For $f>0$, $\frac{2 b+2 \delta+f}{2 \gamma+f}>\frac{b+\delta+\gamma}{b+\gamma}$ is equivalent to $b(2 b+2 \delta+f)>2 \gamma^{2}+f(b+\delta)$. Given that $2 B b>2 \gamma^{2}$, a sufficient condition for welfare to fall is $(2 b-f)>0$ which simply means that the distribution technology is not characterized by rapidly decreasing returns! QED 
The above proposition states that the cost disadvantage arising from the regulation is to the detriment of consumers. This is obvious when both $P$ and $R$ increase, but less so when the price level in small and large retail stores move in opposite directions. The point is that the potential reduction in price applies to a smaller volume of goods than the increase in the price of large integrated retailers. Therefore, the regulation does not have the pro-competitive effect it was intended to have as the response from small retailers cannot make up for the increase in the price in large retail outlets. In Salant and Shaffer (1999), regulation or policy-induced cost asymmetries on Cournot oligopolists increase welfare when the cost increases forced on some firms are offset by cost reductions for other firms, so as to keep the sum of marginal costs constant. In our case, the marginal cost of small retailers remains unchanged and this is why welfare necessarily goes down. Figure 3 relies on the same parameters as Figure 1, except that " $c$ " is allowed to vary. It illustrates the reduction in welfare caused by a tightening of the regulation on the number of employees. We can also see that competition matters as welfare in the presence of 4 integrated distributors is roughly 19\% higher than in the case with 2 integrated distributors. In this example, the welfare effect of competition slowly decreases as the regulation becomes tighter (i.e., “c” increases).

PROPOSITION 2: The effect of the cost-increasing regulation has ambiguous effect on the margin of small independent retailers. If returns in distribution activities are increasing enough, then the regulation induces a decrease in the small retailers' margin. 
PROOF: From equations (8) and (9), we can determine: $\frac{\partial(R-r)}{\partial c}=\frac{n \gamma(2 \delta+f)}{H}$. If $f>0$ (decreasing returns in distribution), then the small retailers' margin widens and more so when $n$ is large, but if $f<0$ (increasing returns in distribution), then $\frac{\partial(R-r)}{\partial c} \leq 0$ as $2 \delta+f \frac{<}{>} 0$. QED

The above proposition tells us that the small retailers' margin may increase or decrease. The higher marginal cost of large retailers makes small stores a relatively more appealing outlet for distributors. Under decreasing returns (or slowly increasing returns: $2 \delta+f>0$ ) in distribution, distributors will want to widen the margin of small retailers to insure that their sales increase. However, if economies of size in distribution are large enough or the marginal cost of small retailers increases slowly $(2 \delta+f<0$ ), the increase in average distribution cost brought about by the regulation-induced drop in the sales of large retailers will incite distributors to tighten the margin of small retailers. "Margin squeezes” were once seen as irrational by antitrust authorities (see Schmalensee, 1973, p.449). Clearly, our result rests on a specific condition that may or may not be realistic even though the food distribution industry is known to have economies of size. Still, Schmalensee's contention that squeezes can be consistent with profit maximization finds support in our analysis.

It had been hoped by the Quebec government that a portion of the retail demand relinquished by large retailers could be acquired by small retailers. From lemma 1, we can see that the change in small retailers' output may be positive or negative : $\frac{\partial x}{\partial c}=\frac{2 \gamma+f}{H} \leq 0$. The output (and the surplus, if it is not acquired by distributors) of small retailers is conditioned by their margin $R-r$ and therefore the factors driving the ambiguity in both cases are similar. In the presence of large economies of size in distribution, the regulation may cause a reduction in the 
margin and sales of the very group it was meant to protect! In the absence of economies of size in distribution, the regulation induces a widening of the small retailers' margin and an increase in sales, but welfare still falls. The removal of the regulation would bring about deeper forward integration and higher welfare. This is not necessarily at odds with the literature which indicates that the welfare consequences of deeper integration are generally mixed. In Salop and Scheffman's (1987) model, backward integration is anti-competitive. In Riordan's (1998) backward integration case, deeper integration has ambiguous welfare effects. Mixed results can also be found for cases of forward vertical integration cases under variable proportions technologies (e.g., Vernon and Graham, 1971; Schmalensee, 1973; Westfield, 1981 and Chung, 1984).

\section{A MINIMUM PRICE IN SMALL RETAIL OUTLETS}

Small retailers have limited space that they must manage carefully. Convenience stores in Quebec devote a lot of space to alcoholic and non-alcoholic beverages. Specifically, beer and milk are important items. Historically, surpermarkets have aggressively priced these items and this is why the Quebec government felt obliged to step in and regulate prices. The Régie des Marchés Agricoles et Alimentaires du Québec (RMAAQ) sets minimum and maximum prices for various types of milk (3.25\%, 2\%, 1\%, 0\% fat) for different sizes of containers (l litre, 2 litres, 4 litres) for 3 regions. Small retailers continue to make representations before the RMAAQ to let it be known that price wars over milk are still eating up their margins. ${ }^{18}$

Minimum prices for beer vary according to the alcohol contents and container sizes. Still small grocery stores continue to lobby for higher minimum beer prices, targeting provincial ministries and agencies that might support their quest. ${ }^{19}$ The stated purpose of the minimum prices is to prevent supermarkets from using predatory pricing strategies against small retailers. 
Theoretically, conditions supporting equilibrium predatory prices usually revolve around capital market imperfections (e.g., Tirole, 1988:377-379) whose significance are questionable in the Canadian retail context. Furthermore, we have shown that small retailers are generally "convenient” for consumers and distributors. If the purpose of minimum prices is not to insure the survival of small retailers, then what are they for and what are their consequences? Even though our model allows for only two goods, it can nevertheless shed some light on the issue.

To gain some intuition regarding the impact of a binding minimum price, consider its effect in a standard Cournot model with a linear demand for a homogenous product and no cost. The minimum price defines a residual demand, $q_{i}^{R}=\operatorname{Max}\left(0, A-P^{\min }-\sum_{j \neq i}^{n} q_{j}\right)$, where the outputs of rival firms are considered as given. Accordingly, there is multiplicity of possible equilibria. However it can be shown that the symmetric equilibrium output, $q^{R}=\frac{A-P^{\min }}{n}$, is decreasing in $P^{\min }$. Since the unrestricted equilibrium price is $P^{e}=\frac{A}{n+1}<P^{\min }$, it follows that $q^{R}<\frac{A}{n+1}=q^{e}$. In our model, the distributors choose the volume of sales of both small and large retailers. Therefore, we can define a residual demand:

$$
x_{i}^{R}\left(q_{i}\right)=\operatorname{Max}\left(0, \frac{a-R^{\min }-b \sum_{j \neq i}^{n} x_{j}-\gamma \sum_{j \neq i}^{n} q_{j}-\gamma q_{i}}{b}\right)
$$

Given that distributors have Cournot conjectures, they take the quantities of rival firms as fixed and the above residual demand defines a simple restriction on a distributor's sales in small retail stores in terms of its sales in its large retail stores. In setting its sales in large stores, the 
distributor must keep in mind that: $\partial x_{i}^{R}(.) / \partial q_{i}=-\gamma / b<0$. Small retailers' supply is governed by $x_{i}=\operatorname{Max}\left(0, \frac{R^{\min }-r}{\delta}\right)$ which provided a strictly positive supply, can be inverted to yield: $r=R^{\min }-\delta x_{i}^{R}\left(q_{i}\right)$. Thus the profit of distributor $i$ can be expressed as follows:

$$
\begin{aligned}
\max _{q_{i}} \pi^{D} & =\left[\left(A-B \sum_{j=1}^{n} q_{j}-\gamma \sum_{j \neq i}^{n} x_{j}-\gamma x_{i}^{R}\right) q_{i}+\left(R^{\min }-\delta x_{i}^{R}\right) x_{i}^{R}+K_{i}\right. \\
& \left.-c q_{i}-\frac{d}{2} q_{i}^{2}-e\left(q_{i}+x_{i}^{R}\right)-\frac{f}{2}\left(q_{i}+x_{i}^{R}\right)^{2}\right]
\end{aligned}
$$

Assuming an interior solution, the first order condition is:

$$
\begin{gathered}
\partial \pi_{i}^{d} / \partial q_{i}=\left(A-B \sum_{j=1}^{n} q_{j}-\gamma \sum_{j=1}^{n} x_{j}\right)-q_{i}\left(\frac{B b-\gamma^{2}}{b}\right)-\left(R^{\min }-2 \delta x_{i}^{R}\right)\left(\frac{\gamma}{b}\right)-c-d q_{i} \\
-e\left(\frac{b-\gamma}{b}\right)-f\left(q_{i}+x_{i}^{R}\right)\left(\frac{b-\gamma}{b}\right)=0
\end{gathered}
$$

If distributors are symmetric, $x_{j}=x, \forall j=1, \ldots n ; \sum_{j=1}^{n} x_{j}=n x, q_{j}=q, \forall j=1, \ldots n ; \sum_{j=1}^{n} q_{j}=n q \quad$ and $x_{i}^{R}=x=\frac{a-R^{\min }-\gamma n q}{b n}$, then the above first order condition can be expressed as:

$\frac{1}{b^{2} n}\left\{\begin{array}{l}-b^{3} n^{2} q-b^{2} n(c+d+e+f+B q)+b\left[n \gamma(e+(n+1) \gamma q)+f\left(R^{\min }+n \gamma(q+1)\right)\right]- \\ \gamma\left(R^{\min }+n \gamma q\right)(f+2 \delta)+a\left[b^{2} n-b(f+n \gamma)+\gamma(f+2 \delta)\right]\end{array}\right\}=0$

The second order condition requires that: $-G<0$, where $G \equiv n\left[b^{2} B+b^{3} n-b \gamma(f+\gamma(n+1))+\gamma^{2}(f+2 \delta)\right]>0$. The parameters for the slopes of the demand functions which governs the speed at which marginal revenues fall must be large enough to counter potential economies of size $(f<0)$ and product substitution effects $(\gamma)$. Solving for the equilibrium level sales by large retailers, we obtain: 
$n q=\frac{-b^{2} n(c+d+e+f)+b\left(f R^{\min }+e \gamma n+f \gamma n\right)-R^{\min } \gamma(f+2 \delta)+a\left(b^{2} n-b(f+n \gamma)+\gamma(f+2 \delta)\right)}{G}$

The symmetric equilibrium level of sales by small retailers is obtained by replacing " $n q$ " in the following equation: $n x=\frac{a-R^{\min }-\gamma n q}{b}$.

PROPOSITION 3: An increase in the minimum price in small retail stores $\left(R^{\text {min }}\right)$ reduces the volume sold by small retail stores, but it has an ambiguous effect on the volume sold by large retailers.

PROOF: Given that $\frac{\partial n q}{\partial R^{\min }}=\frac{b f-\gamma(f+2 \delta)}{G}$ and from the residual demand linking the volume sold in small and large stores, we find that $\frac{\partial n x}{\partial R^{\min }}=\frac{\left[-G-\gamma\left(\partial n q / \partial R^{\min }\right)\right]}{b G}=\frac{-b B-b^{2} n+\gamma^{2}(1+n)}{G}$. Because $b B>\gamma^{2}$ and $b^{2} n>\gamma^{2} n$, it follows that $\frac{\partial n x}{\partial R^{\min }}<0$. The effect on the sales of large retailers can be ascertained by noting that $\operatorname{sign}\left(\frac{\partial n q}{\partial R^{\min }}\right)=\operatorname{sign}(b f-\gamma(f+2 \delta))$. If $f \leq 0$, then $(b-\gamma) f-2 \gamma \delta<0$. However if $f>0$, then $(b-\gamma) f-2 \gamma \delta \frac{\geq}{<} 0$ as $f \frac{\geq}{<b-\gamma} \frac{2 \gamma \delta}{b}$. QED

Since distribution activities are known to be characterized by increasing returns even at high levels of outputs, the above proposition indicates that a binding minimum price in small retail stores is likely to trigger a reduction in the volume sold by small and large stores. When this happens, welfare must decrease according to lemma 2 as distributors endowed with market power that were distributing too little without the price regulation end up distributing even less. In fact, the reductions of both $n q$ and $n x$ insure that both retail prices increase, an outcome which 
is bad for consumers. Welfare goes down because the price restriction in small retail stores diminishes the degree of competition at the retail level.

PROPOSITION 4. An increase in a binding minimum price in small retail stores bring about a “margin squeeze” on small retailers.

PROOF: Given that $r=R^{\min }-\delta x$ and that $\frac{\partial x}{\partial R^{\min }}=\frac{-b B-b^{2} n+\gamma^{2}(1+n)}{n G}<0$, then $\frac{\partial\left(R^{\min }-r\right)}{\partial R^{\min }}=\delta \frac{\partial x}{\partial R^{\min }}<0 . \quad$ QED

The margin squeeze in proposition 4 arises because of a significant cost predation effect. Hastings and Gilbert (2005) recently uncovered empirical evidence of cost predation effects induced by vertical integration in the petroleum/gasoline industry in the United States. The structure of this industry resembles that of the food distribution/retail industry as a few very large refineries supply their own retail outlets as well as non-integrated retailers. Our results suggest that small stores' recriminations about being squeezed by integrated distributors are likely to be grounded.

\section{POLICY IMPLICATIONS AND CONCLUSIONS}

The food distribution and retail sectors are highly concentrated and integrated. Large distributors are forwardly integrated in the retail business and as such compete with small retailers they sell inputs to. The stylized facts about the industry are that there are economies of size in distribution and that larger retail stores have a cost advantage over smaller stores. The concentration build up in distribution and the increasing size of retail outlets are the outcome of long term trends. For 
years, small retailers concerned about their margin (and survival) and have asked the government to intervene. In the province of Quebec, the government decided to restrict the number of employees that large retailers are allowed to use during certain hours. The purpose of this regulation is to reduce the cost advantage of larger retailers. It was hoped that large food retailers would prefer to close rather than to operate with a much reduced staff and that smaller stores would become more profitable. Naturally, the regulation was controversial when it was enacted in 1992 and it remains so even though the regulation was slightly relaxed at the end of 2006. The government also regulates prices of popular items sold in convenience stores like milk and beer and that too is controversial.

The reasons motivating government intervention are similar to those justifying interventions to slow down the erosion in the number of small farms. As for the number of farms, it looks like the number of small retailers will continue to fall as new large players enter the market and changes in technology keeps on favoring larger stores. Thus, the eventual arrival of Walmart's supercentres in Quebec would reduce the demand for "convenience”, but it would be welfare-enhancing. We show that the margin of small retailers gets squeezed in the presence of a minimum retail price. The price level in large stores also tends to increase, thus reducing consumer surplus and welfare. Furthermore, a regulation that artificially increases the marginal retail cost of large retail outlets reduces welfare. Its effect on the small retailers' margin is ambiguous. Several of our results about large and small retailers depend on the technology used in distribution. This highlights the importance of vertical linkages in the analysis of regulations at a given level in the marketing chain. Finally, given that the two regulations analyzed decrease welfare and may even have a perverse effect on the small retailers' margin, we are left wondering about the raison d'être of these regulations. Quebec's regulation restricting the colour of 
margarine was just abolished (July 2008) and perhaps this will mark a new "no non-sense" approach to food policy and regulations. 


\section{REFERENCES}

Bonroy, O. and Larue, B. "Forward Vertical Integration: The Fixed-Proportion Case Revisited.” Economics Bulletin, 12, 25:1-9.

Chung, K. S. 1984. "Forward Integration by a Monopolist: Some Extensions." Southern Economic Journal, 50:690-710.

Church, J. and Ware, R. 2000. Industrial Organization: A Strategic Approach. Toronto: IrwinMcGraw-Hill.

Hart, O. and Tirole, J. 1990. "Vertical Integration and Market Foreclosure.” Brookings Papers on Economic Activity, Special Issue: 205-76.

Hastings, J.S. and Gilbert, R.J. 2005. "Market Power, Vertical Integration and the Wholesale Price of Gasoline”, The Journal of Industrial Economics, 53:469-492.

Larue, B. and Gervais, J.P. (2002). "Welfare-Maximizing and Revenue-Maximizing Tariffs with a Few Domestic Firms”, Canadian Journal of Economics, 35:786-804.

Loblaws. 2005. Annual Report. http://www.loblaw.ca/en/inv_ar.html\#

McAfee, R.P. 2002. Competitive Solutions: The Strategist's Toolkit. Princeton: Princeton University Press.

Needham, D. 1969. Economic Analysis and Industrial Structure. New York: Holt, Rinehart and Winston Inc..

Ordover, J.A., Saloner, G. and Salop, S.C. 1990. “Equilibrium Vertical Foreclosure.” American Economic Review, 80:127-42.

Perry, M.K. 1978. "Vertical Integration: The Monopsony Case.” American Economic Review, 68:561-70.

Perry, M.K. 1989. “Vertical Integration: Determinants and Effects”. In R.D. Schmalensee and Willig, R.D. eds., Handbook of Industrial Organization vol.1, Amsterdam: North Holland: 183-255.

Quirmbach, H. C. 1992. “Sequential Vertical Integration.” Quarterly Journal of Economics, 107: 1101-11.

Riordan, M.H. and Salop, S.C. 1995. "Evaluating Vertical Mergers: A Post-Chicago Approach.” Antitrust Law Journal, 63:513-68.

Riordan, M. H. 1998. “Anti-Competitive Vertical Integration by a Dominant Firm.” American Economic Review, 88:1232-1248. 
Salinger, M.A. 1988. "Vertical Mergers and Market Foreclosure." Quarterly Journal of Economics, 103:345-56.

Salant, S.W. and Shaffer, G. 1999. Unequal Treatment of Identical Agents in Cournot Equilibrium, American Economic Review, 89:585-604.

Salop, S.C. and Scheffman, D.T. 1987. “Cost-Raising Strategies.” The Journal of Industrial Economics, 36:19-34.

Schmalensee, R. 1973. "A Note on the Theory of Vertical Integration.” The Journal of Political Economy, 81:442-449.

Tirole, J. 1988. The Theory of Industrial Organization. Cambridge MA, MIT Press.

Vernon, J.M. and Graham, D.A. 1971. "Profitability of Monopolization by Vertical Integration.” The Journal of Political Economy, 79:924-925.

Vives, X. 1999. Oligopoly Pricing: Old Ideas and New Tools. Cambridge MA, MIT Press.

Westfield, F.M. 1981. “Vertical Integration: Does Product Price Rise or Fall?” American Economic Review, 71:334-346. 


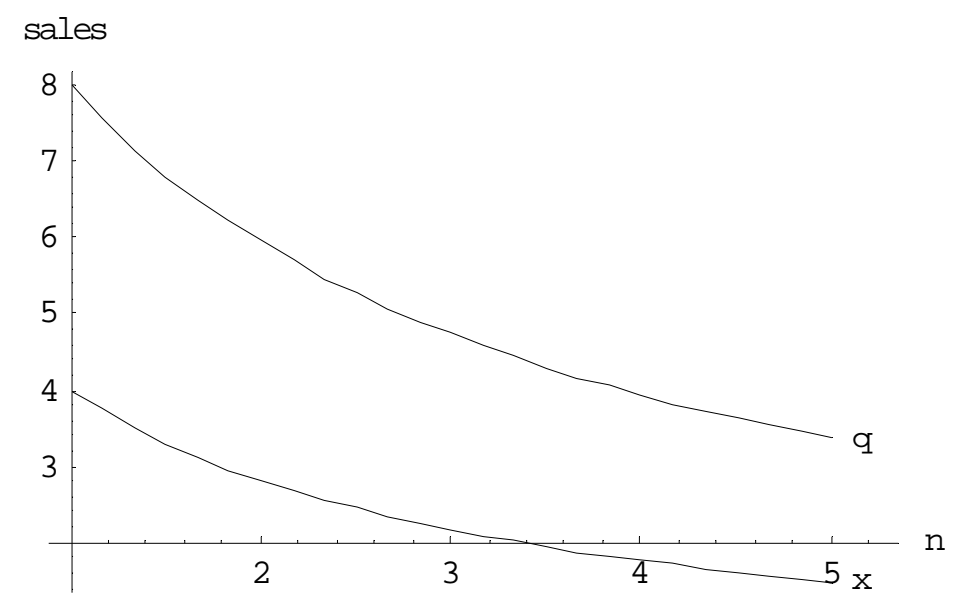

Figure 1 . Sales by integrated retailers and small retailers sharing same technology

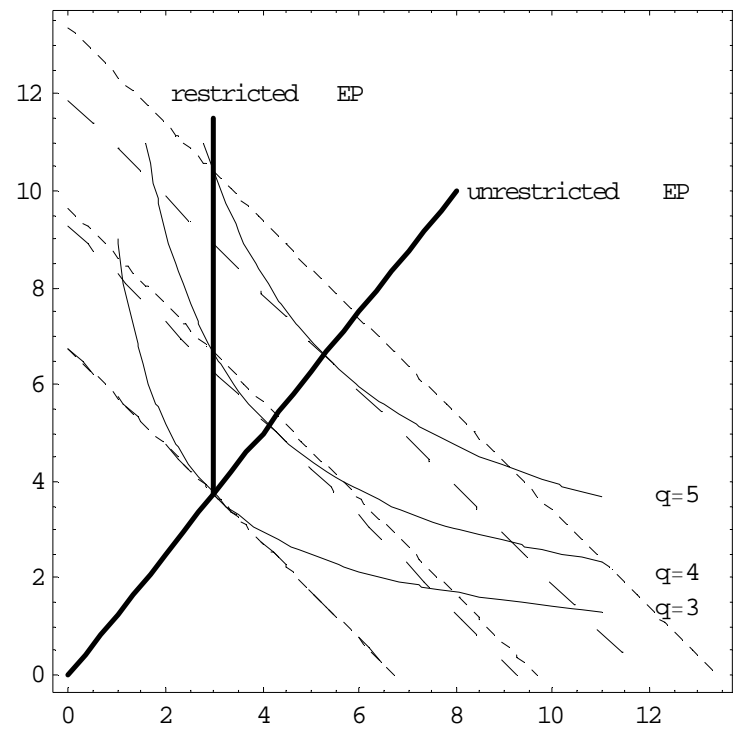

Figure 2. Cost increases associated with a constraint on the number of employees 


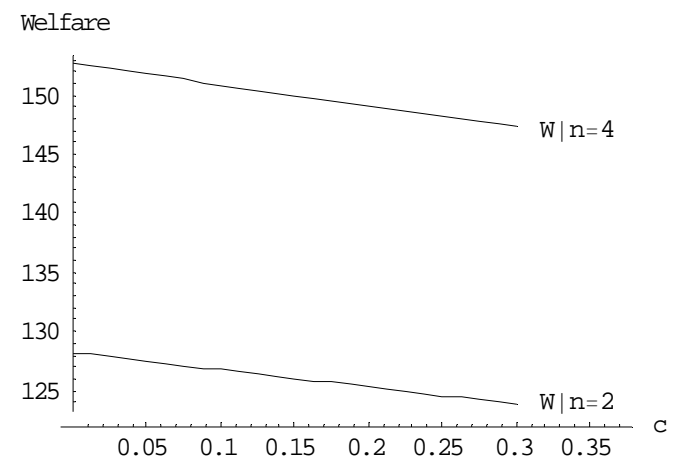

Figure 3. Regulation-induced cost increases, welfare and the number of firms 


\section{TECHNICAL APPENDIX}

\section{Appendix 1:}

Totally differentiating the first order conditions of a given distributor $i$ yields the following:

$$
\begin{gathered}
{\left[\begin{array}{ll}
-(2 B+d+f) & -(2 \gamma+f) \\
-(2 \gamma+f) & -(2 b+2 \delta+f)
\end{array}\right]\left[\begin{array}{l}
d q_{i} \\
d x_{i}
\end{array}\right]=\left[\begin{array}{l}
-1 \\
0
\end{array}\right] d A+\left[\begin{array}{l}
0 \\
-1
\end{array}\right] d a+\left[\begin{array}{l}
\sum q_{j}+q_{i} \\
0
\end{array}\right] d B+\left[\begin{array}{l}
0 \\
\sum x_{j}+x_{i}
\end{array}\right] d b+} \\
{\left[\begin{array}{l}
\sum x_{j}+x_{i} \\
\sum q_{j}+q_{i}
\end{array}\right] d \gamma+\left[\begin{array}{l}
1 \\
0
\end{array}\right] d c+\left[\begin{array}{l}
q_{i} \\
0
\end{array}\right] d \mathrm{~d}+\left[\begin{array}{l}
1 \\
1
\end{array}\right] d e+\left[\begin{array}{l}
q_{i}+x_{i} \\
q_{i}+x_{i}
\end{array}\right] d f+\left[\begin{array}{l}
0 \\
2 x_{i}
\end{array}\right] d \delta}
\end{gathered}
$$

The second order condition requires that the determinant of the first matrix be positive, hence $H \equiv-(f+2 \gamma)^{2}+(2 B+f+d)(2 b+f+2 \delta)>0$. Subscripts and summations can be dispensed with under the symmetry assumption (i.e., $q_{i}=q, \forall i ; \sum q_{j}=n q$ ) and comparative statics can be performed with Cramer's rule.

$$
\begin{aligned}
& \frac{\partial q}{\partial A}=\frac{\left|\begin{array}{ll}
-1 & -(2 \gamma+f) \\
0 & -(2 b+2 \delta+f)
\end{array}\right|}{H}=\frac{2 b+2 \delta+f}{H}>0, \frac{\partial x}{\partial A}=\frac{\left|\begin{array}{l}
-(2 B+d+f)-1 \\
-(2 \gamma+f)
\end{array}\right|}{H}=\frac{-2 \gamma-f}{H} \frac{<}{<} 0 \\
& \frac{\partial q}{\partial a}=\frac{-2 \gamma-f}{H} \frac{>}{<} 0, \quad \frac{\partial x}{\partial a}=\frac{2 B+d+f}{H}>0, \quad \frac{\partial q}{\partial B}=\frac{-(n+1) q(2 b+2 \delta+f)}{H}<0, \\
& \frac{\partial x}{\partial B}=\frac{(n+1) q(2 \gamma+f)}{H} \frac{>}{<} 0, \quad \frac{\partial q}{\partial b}=\frac{(n+1) x(2 \gamma+f)}{H} \frac{>}{<} 0, \quad \frac{\partial x}{\partial b}=\frac{-(n+1) x(2 b+d+f)}{H}<0, \\
& \frac{\partial q}{\partial \gamma}=\frac{(n+1)[q(2 \gamma+f)-x(2 b+2 \delta+f)]}{H} \frac{>}{<} 0, \quad \frac{\partial x}{\partial \gamma}=\frac{(n+1)[x(2 \gamma+f)-q(2 B+d+f)]}{H}<0, \\
& \frac{\partial q}{\partial c}=\frac{-(2 b+2 \delta+f)}{H}<0, \quad \frac{\partial x}{\partial c}=\frac{2 \gamma+f}{H} \frac{>}{<} 0, \quad \frac{\partial q}{\partial d}=\frac{-q(2 b+2 \delta+f)}{H}<0, \quad \frac{\partial x}{\partial d}=\frac{q(2 \gamma+f)}{H} \underset{<}{<}, \\
& \frac{\partial q}{\partial e}=\frac{-2(b+\delta-\gamma)}{H}<0, \quad \frac{\partial x}{\partial e}=\frac{-2\left(B+\frac{d}{2}-\gamma\right)}{H}<0, \quad \frac{\partial q}{\partial f}=\frac{-2(q+x)(b+\delta-\gamma)}{H}<0, \\
& \frac{\partial x}{\partial f}=\frac{-2(q+x)\left(B+\frac{d}{2}-\gamma\right)}{H}<0, \frac{\partial q}{\partial \delta}=\frac{2 x(2 \gamma+f)}{H} \geq 0, \frac{\partial x}{\partial \delta}=\frac{-2 x(2 B+d+f)}{H}<0 .
\end{aligned}
$$




\section{ENDNOTES}

\footnotetext{
${ }^{1}$ See http://www.radio-canada.ca/actualite/lepicerie/docArchives/2004/02/12/enquete.shtml for more information.

2 For more details see for example: http://www.radio-canada.ca/nouvelles/Economie-Affaires/2006/09/07/004epiciers-heures-quebec.shtml.
}

${ }^{3}$ The fines for first-time, second-time and third-time offenders are $\$ 1500, \$ 6000$ and $\$ 9000$ respectively. It has also been reported that some employees have been asked to work in plain clothes to minimize suspicion. See http://lapresseaffaires.cyberpresse.ca/article/20080320/LAINFORMER/80320205/5891/LAINFORMER01 for more details.

${ }^{4}$ Several authors have worked on the pro and anti-competitive effects of deeper vertical integration. The interested reader is referred to Salinger (1988), Perry (1978, 1989), Ordover et.al. (1990), Hart and Tirole (1990) and Riordan and Salop (1995).

${ }^{5}$ The market shares of Loblaws, Metro and Sobeys were 33\%, 27\% and 18\% respectively in 2002. For more details, see http://www.mapaq.gouv.qc.ca/Fr/md/statistiques/distribution/. Costco is also a player in the Quebec food market, but its share is conjectured to be around 6\%. The market has changed radically since the 1970s when Steinberg was the dominant firm competing against A\&P Canada who owned Dominion and A\&P stores and Metro, Provigo and IGA who were small players then. Steinberg went from a small family business to a huge empire under the management of Sam Steinberg. A family feud over his succession brought about the demise of the company whose stores ended up in the hands of fast-growing Provigo and Metro in 1992, who in turn subsequently sold a few stores to IGA to appease competition concerns. Provigo was purchased by Loblaw Companies Limited in 1998 and Metro bought A\&P Canada in 2005 from The Great Atlantic and Pacific Tea Company, a German-owned retailer based in the United States.

${ }^{6}$ See http://www.mapaq.gouv.qc.ca/Fr/md/statistiques/distribution/

${ }^{7}$ Wal-Mart spokesman Yanik Deschênes said in a recent interview that none of the new supercentres would open in Quebec because of logistical and marketing reasons. Wal-Mart hasn't yet brought its supercentre concept to Quebec, because the company doesn't have a distribution centre in the province. Wal-Mart is still getting used to catering to Canadian customers, who have different tastes from the company's U.S. shoppers. Quebec consumers, shop differently than customers in the rest of Canada. "Before launching in Quebec we'd have to adjust our offering," he said (Montreal Gazette, May 9, 2008).

${ }^{8}$ See http://www.metro.ca/corpo/profil-corpo/historique/2003.en.html.

${ }^{9}$ The North American couche-tard network is made up of over 5000 stores located in 6 Canadian provinces, 25 US states. See http://www.couche-tard.com/en/entreprise/profile.html.

${ }^{10}$ See p.9 of Loblaws 2005 annual report at http://www.loblaw.ca/en/inv_ar.html\#

${ }^{11}$ See http://www.statcan.ca/english/research/11-621-MIE/11-621-MIE2006038.htm.

${ }^{12}$ Let $P$ and $r$ be the prices at which downstream firms sell their output to consumers and purchase their inputs from a sole upstream supplier whose cost of production is $C(x)$. One unit of output requires one unit of input and the processing cost is $c$, a constant. The problem of the upstream firm can be written as: Max $\mathfrak{I}=r x-C(x)$ s.t. $P(x)=r+c$. The resulting behavioural rule, $P+P^{\prime} x-c-C^{\prime}=0$, turns out to be the same as that of an integrated firm maximizing $P(x) x-c x-C(x)$. See also Chung's (1984) proposition 1.

${ }^{13}$ In fact, this is also the case in Quirmbach (1992), even though the downstream production is done with a technology giving rise to a U-shaped average cost curve. 
${ }^{14}$ The hypothesis that each type of stores sells a unique product allows us to make our arguments in the simplest manner. Large grocery stores sell thousands of products, but because the product offering of large stores does not change much from store to store, our assumption is not that heroic. McAfee (2002, chap.11) also assumes product homogeneity to analyze price dispersion (and mixed equilibrium strategies) at the food retail level.

${ }^{15}$ Our modelling of the small retailers is inspired from Salop and Scheffman (1987) who did not explicitly introduce the number of firms in the competitive fringe.

${ }^{16}$ As in Salop and Scheffman (1987) and Riordan (1998) monopoly models, the small downstream firms have an upward-sloping supply curve, which gives rise to rents. $K_{i}$ can be thought as a franchise fee, as in Tirole (1988, p.176), and we assume that it is used by the distributors to extract all of the rents generated by the small retailers, that is: $K_{i}=\pi_{i}(R, r)=\frac{(R-r)^{2}}{2 \delta}$, which is obtained by inserting the small retailers' supply function into the expression for profit.

${ }^{17}$ The model is general enough to admit no integration and full integration cases by middling with the costs parameters but these corner solutions are of meager interest in the present case.

18 To counter the downward rigidity of prices, Supermarkets frequently advertise that they sell milk at the minimum prices allowed by the law. See http://www.amdeq.ca/Fichiers\%20PDF/Num\%E9ro\%2010\%20TU.pdf

19 Besides the competition argument, it is alleged that higher minimum beer prices could alleviate financial pressures on the public health care costs and on the no-fault government car insurance program. See http://www.amdeq.ca/Fichiers\%20PDF/Num\%E9ro\%209\%20TU.pdf 